\title{
UJI AKTIVITAS ANTIPLASMODIUM FRAKSI N-HEKSANA DAUN Peronema canescens TERHADAP Mus musculus
}

\author{
Fenny Andriani*'1, Agus Sundaryono², Nurhamidah ${ }^{3}$ \\ Program Studi Pendidikan Kimia Fakultas Keguruan dan Ilmu Pendidikan Universitas Bengkulu \\ ${ }^{1,2,3}$ Program Studi Pendidikan Kimia, jurusan PMIPA, FKIP, Universitas Bengkulu \\ *11e-mail: fennyandriani42@gmail.com
}

\begin{abstract}
Peronema canescens (Sungkai) has been used in Bengkulu as raw herbal remedy to reduce the fever, some people are using as a malaria drug. $P$. canescens leaves contain alkaloids, flavonoids, tannins and terpenoids - steroids . This study aims to analyze the effect of $P$. canescens leaves n-hexane fraction. against paracetemias in Mus musculus infected with Plasmodium berghei, then to prove whether the .P. canescens leaves $\mathrm{n}$-hexane fraction has potential as alternative medicine for malaria. To make $P$. canescens extract, leaves was macerated using $\mathrm{EtOH}(96 \%)$, then filtrate was evaporated using a rotary evaporator, then fractionated with n-hexane. The 25 healthy M.musculus weighing 20-40g each, infected with P.berghei, grouped into 5 ie group 1 (K-) was treated orally with aquades, group $2(\mathrm{~K}+)$ was treated orally with $0.42 \mathrm{mg}$ of Chloroquine, Group 3 (P1) Group 4 (P2), group 5 (P3) was treated orally with a $P$. canescens leaves n-hexane fraction each at a dose of $0.028,0.056$ and $0.084 \mathrm{~g} / \mathrm{kgBW}$. After 3 days of digestion for each treatment, the amount of erythrocytes was calculated under a microscope. : The giving of the with dose $0,028 \mathrm{~g} / \mathrm{kgBW}$ able to inhibit paracetemia $33,49 \%, 0,056 \mathrm{~g} / \mathrm{kgBW}$ able to $57.91 \%$ and $0,084 \mathrm{~g} / \mathrm{kgBW}$ able to $61.69 \%$ The conclusion is the $P$. canescens leaves $\mathrm{n}$-hexane fraction at a dose of $0.028,0.056$, and $0.084 \mathrm{~g} / \mathrm{kgBW}$ orally wil be decreased the amount of paracetemia in M.musculus, and the higher the dose given the higher percent of the inhibition.
\end{abstract}

Keywords: Peronema canescens, Mus musculus, Plasmodium berghei.

\begin{abstract}
Abstrak
Peronema canescens (Sungkai ) oleh masyarakat Bengkulu digunakan sebagai obat herbal untuk menurunkan panas, dan sebagian masyarakat menggunakan rebusan daun $P$. canescens sebagai obat malaria. Daun tanaman $P$. canescens mengandung senyawa alkaloid, flavonoid, tanin dan terpenoid - steroid. Penelitian ini bertujuan untuk mengukur pengaruh pemberian fraksi n-heksan daun $P$. canescens terhadap jumlah parasetemia pada Mus musculus yang diinfeksi Plasmodium berghei, kemudian menganalisa apakah fraksi n-heksan daun $P$. canescens berpotensi sebagai obat alternatif penyakit malaria . Daun kering $P$. canescens di maserasi menggunakan EtOH (96\%), filtrat diuapkan menggunakan rotary evaporator, kemudian difraksinasi dengan n-heksana. 25 ekor M.musculus sehat dengan berat 20-40g diinfeksi dengan P.berghei, kemudian dikelompokkan menjadi 5 yaitu kelompok 1 (K-) diberi perlakuan secara oral dengan aquades, kelompok $2(\mathrm{~K}+)$ diberi perlakuan secara oral dengan $0,42 \mathrm{mg}$ Klorokuin, kelompok $3\left(\mathrm{P}_{1}\right)$, kelompok $4\left(\mathrm{P}_{2}\right)$, kelompok $5\left(\mathrm{P}_{3}\right)$ diberi perlakuan secara oral dengan fraksi n-heksana daun Peronema canescens sungkai masing- masing dengan dosis 0,028, 0,056 dan 0,084 g/kgBB. Setelah 3 hari digavage untuk setiap perlakuan, jumlah eritrosit dihitung di bawah mikroskop. Pemberian fraksi n-heksana daun P.canescens sungkai secara oral pada M. musculus dengan dosis $0,028 \mathrm{~g} / \mathrm{kgBB}$ mampu menghambat persen parasetemia sebesar $33.49 \%$, dosis $0,056 \mathrm{~g} / \mathrm{kgBB}$ sebesar $57.91 \%$ dan dosis $0,084 \mathrm{~g} / \mathrm{kgBB}$ sebesar $61.69 \%$. Pemberian fraksi n-heksana daun $P$. canescens dengan dosis $0,028,0,056$, dan $0,084 \mathrm{~g} / \mathrm{kgBB}$ secara oral mampu menurunkan jumlah parasetemia pada M.musculus, dan semakin tinggi dosis yang diberikan semakin tinggi persen penghambatannya.
\end{abstract}

Kata kunci : Peronema canescens, Mus musculus, Plasmodium berghei.

\section{PENDAHULUAN}

Tumbuhan obat adalah salah satu sumber senyawa yang berkhasiat untuk mengobati berbagai penyakit. [1,2] Hal ini menjadi penting karena tanaman banyak mengandung berbagai senyawa-se-nyawa metabolit sekunder seperti terpenoid, steroid, alkaloid, flavonoid, saponin, tanin dan fenolik yang umumnya mempunyai kemampuan bioaktifitas [3] sehingga sangat berpotensi sebagai sumber baru obat [4]. Salah satu jenis tanaman yang telah digunakan oleh masyarakat di daerah Bengkulu sebagai obat tradisional untuk mengobati penyakit infeksi seperti malaria adalah
Peronema canescens (Sungkai). Seperti pada suku Lembak Delapan di daerah Bengkulu, diketahui bahwa tanaman $P$. canescens merupakan bahan baku obat herbal untuk menurunkan panas [5], dan rebusan daunnya secara tradisional juga digunakan oleh penduduk lokal Curup, Provinsi Bengkulu sebagai obat penyakit malaria [6]. Sampai saat ini, penyakit malaria masih menjadi masalah yang serius di Indonesia, apalagi provinsi Bengkulu telah dikategorikan sebagai daerah zona merah penderita malaria, [7]. ditambah lagi adanya resistensi parasit terhadap obat-obatan antiplasmodium seperti klorokuin [8]. Karena itu perlu dilakukan penelitian lebih lanjut untuk mencari ta- 
naman yang berpotensi sebagai obat alternatif terhadap malaria.

Penelitian ini bertujuan untuk mengukur pengaruh pemberian fraksi n-heksan daun $P$. canescens terhadap jumlah parasetemia pada Mus musculus yang diinfeksi Plasmodium berghei, kemudian menganalisa apakah fraksi n-heksan daun $P$. canescens berpotensi sebagai obat alternatif untuk penyakit malaria

\section{METODE PENELITIAN}

Daun $P$. canescens segar dicuci bersih kemudian dipotong kecil-kecil dan dilakukan pengeringan dengan cara diangin-anginkan, kemudian di maserasi dengan etanol $96 \%$ selama 7 hari. Hasil maserasi diuapkan, kemudian di fraksinasi dengan pelarut n-heksana. Hasil fraksinasi dipekatkan dengan penguapan menggunakan seperangkat rotary evaporator sehingga diperoleh fraksi n-heksana daun $P$. canescens .

M.musculus jantan diadaptasikan di dalam kandang selama beberapa hari. Setelah diadaptasi, $M$. musculus jantan dibagi ke dalam 5 kelompok. Pada setiap kelompok, kelompok control negative $-M$. musculus yang diinfeksi $P$. berghei diberi aquades secara oral, kontrol positif diberi kloroquin, kelompok perlakuan $\mathrm{P}_{1}, \mathrm{P}_{2}$, dan $\mathrm{P}_{3}$ yang merupakan M.musculus yang diinfeksi P.berghei diberi fraksi n-heksan daun P.canescens dengan dosis secara berturut-turut 0,028 , 0,056 dan 0,084 g/KgBB.

Dalam menggunakan dosis efektif 0,028, 0,056 dan $0,084 \mathrm{~g} / \mathrm{Kgbb}$ digunakan dosis yang disesuaikan dengan berat M.Musculus.[9] Konversi dosis efektif fraksi n-heksana daun sungkai yang diberikan pada $M$. musculus dengan berat rata-rata $35 \mathrm{~g}$, untuk dosis $0,028 \mathrm{~g} / \mathrm{KgBB}$ adalah $0,166 \mathrm{~mL}$, dosis 0,056 $\mathrm{g} / \mathrm{KgBB}$ adalah $0,33 \mathrm{~mL}$, sedangkan dosis 0,084 $\mathrm{g} / \mathrm{KgBB}$ adalah $0,5 \mathrm{~mL}$.

Pengembangan P.berghei dilakukan dengan cara mengambil darah M.musculus yang diinfeksi dengan menggunakan spuit injeksi yang telah diisi dengan antikoagulan EDTA sebanyak $0,1 \mathrm{~mL}$, selanjutnya diinjeksikan ke $M$. musculus yang belum terinfeksi $P$. berghei dengan volume $0,2 \mathrm{~mL}$ secara intraperitonial.

Untuk mengetahui jumlah eritrosit $M$. musculus yang telah terinfeksi $P$. berghei dilakukan dengan cara memotong ekor $M$. musculus sepanjang 0,1 mm, bagian pangkal ekor di tarik sampai ke ujung supaya darah M. musculus keluar, kemudian darah tersebut dibuat apusan di atas kaca preparat.

Perhitungan parasetemia adalah presentase dari sel darah merah yang terinfeksi malaria.

$\%$ parasetemia $=\frac{\text { jumlah eritrosit yang terinfeksi }}{\text { jumlah eritrosit }} \times 100$
$\%$ pertumbuhan $=\frac{P(d 2-d 1)+P(d 3-d 2)+\cdots+P(d 7-d 6)}{6}$

$\%$ penghambatan $=100-\left[\frac{X e}{X k} \times 100\right]$

Keterangan:

$\mathrm{Xe}=\%$ pertumbuhan rata-rata parasit pada tiap kelompok uji

$\mathrm{Xk}=\%$ pertumbuhan rata-rata parasit pada tiap kelompok kontrol negative

$\mathrm{P}[\mathrm{dx}-(\mathrm{dx}-1)]=\%$ parasetemia hari ke-x dikurangi dengan $\%$ parasetemia hari sebelumnya

Data yang diperoleh dari hasil uji kuantitatif pada $M$. musculus yang terinfeksi $P$. berghei dilakukan analisa One Way Anova. Rumus anova yang digunakan adalah:

$\mathrm{FK}=\frac{\left(\sum x\right)^{2}}{n(k)}$

$\mathrm{JK}$ Total $=\sum \mathrm{X}^{2}-\frac{\left(\sum X\right)^{2}}{n(k)}$

$\mathrm{JK}$ perlakuan $=\frac{\sum\left(\sum X i\right)^{2}}{n}-\frac{\left(\sum X\right)^{2}}{n(k)}$

Varian $(\mathrm{KT})$ perlakuan $=\frac{J K \text { perlaukan }}{K-1}$

$\mathrm{JK}=\mathrm{JK}$ total $-\mathrm{JK}$ perlakuan

Varian $(\mathrm{KT})$ Galat $=\frac{J K \text { Galat }}{k(n-1)}$

$\mathrm{F}$ Hitung $=\frac{\text { varian perlakuan }}{\text { varian galat }}$

Keterangan :

$\mathrm{FK}=$ faktor koreksi, JK = Jumlah Kuadrat ,

Varian $=$ kuadrat tengah

Apabila F hitung > F tabel, maka menunjukkan hasil yang signifikan atau $\mathrm{H} 1$ diterima dan $\mathrm{H} 0$ ditolak, dan apabila $\mathrm{H} 1$ diterima dilanjutkan dengan uji DMRT.

\section{HASIL DAN PEMBAHASAN}

Tanaman yang digunakan dalam penelitian ini adalah tanaman P.canescens yang diperoleh di daerah Tugu Hiu, Kota Bengkulu. Bagian yang digunakan dalam penelitian ini adalah daun.

Daun P.canescens segar yang digunakan sebanyak $7658 \mathrm{~g}$, lalu dikeringkan. Berat sampel ke-ring yang diperoleh adalah 3254 g. Sampel kering dimaserasi, kemudian sejumlah filtrat dipekatkan dengan rotaty evaporator dan diperoleh ekstrak etanol sebanyak 248 g. Ekstrak kental tersebut selanjutnya difraksinasi dengan n-heksana dan diuapkan, sehingga diperoleh fraksi n-heksana daun P.canescens sebanyak 14,39 g. Berdasarkan Tabel 1, rendemen fraksi nheksana daun $P$. canescens terhadap sampel kering adalah sebesar $0,44 \%$. 
Tabel 1. Data Rendemen Daun P.canescens

\begin{tabular}{ccccc}
\hline \multirow{2}{*}{ No } & Daun Sungkai & \multicolumn{3}{c}{ Rendemen Daun Sungkai } \\
\cline { 3 - 5 } & Ekstrak kasar & $\begin{array}{c}\text { Sampel Segar } \\
(7658 \mathrm{~g})\end{array}$ & $\begin{array}{c}\text { Sampel Kering } \\
(3254 \mathrm{~g})\end{array}$ & $\begin{array}{c}\text { Ekstrak Kental Etanol } \\
(248 \mathrm{~g})\end{array}$ \\
\hline 1 & Fraksi n-heksana $(14,39 \mathrm{~g})$ & $3,23 \%$ & $7,62 \%$ & - \\
2 & $0,19 \%$ & $0,44 \%$ & $5,80 \%$ \\
\hline
\end{tabular}

Fraksi n-heksana daun P.canescens yang sudah di evaporasi, selanjutnya diuji aktivitas biologisnya kepada $M$. musculus dengan berat badan rata-rata $35 \mathrm{~g}$. M. musculus yang digunakan berjenis kelamin jantan karena tidak terjadi fluktuasi hormon yang dapat menyebabkan suhu tubuh M.musculus lebih tinggi $\pm 0,3$ $0,6{ }^{0} \mathrm{C}$ di atas suhu biasa $\left(36,5{ }^{0} \mathrm{C}-38,0{ }^{0} \mathrm{C}\right)$, akibat dari pengeluaran hormon progesteron pada masa ovulasi dan bentuk pertahanan homeostatis sekresi hormon yang diatur oleh hipotalamus.

Dari Gambar 1 mengenai pengamatan apusan sel darah M.musculus pada mikroskop cahaya dengan perbesaran 100x, menunjukkan perbedaan karakteristik antara eritrosit normal dan yang terinfeksi. Eritrosit normal berwarna kekuningan dan tidak ada inti, sedangkan yang terinfeksi memiliki titik-titik dan lebih besar dibandingkan normal serta berwarna lebih pucat.
Perbedaan karakteristik tersebut disajikan pada Gambar 1.

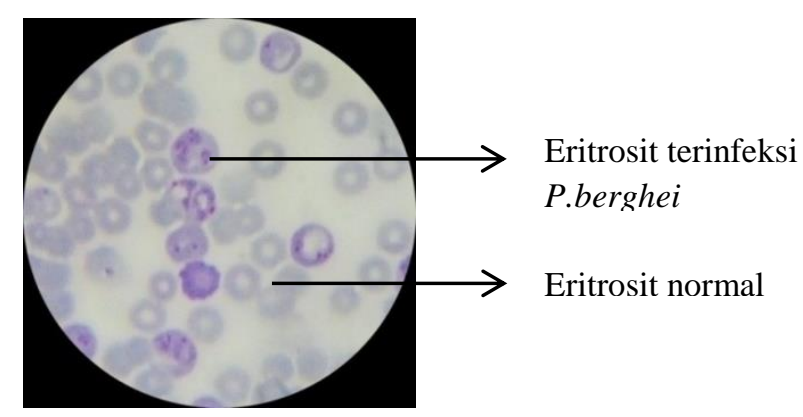

Gambar 1. Eritrosit Mencit Jantan

Dari total 25 ekor M.musculus, dengan 5 perlakuan dan 5 ulangan didapat hasil ratarata jumlah eritrosit M.musculus jantan yang terinfeksi P.berghei seperti dalam Tabel 2.

Tabel 2. Rata-Rata \% Parasetemia M.musculus Jantan

\begin{tabular}{|c|c|c|c|c|c|c|c|c|}
\hline \multirow{3}{*}{ Perlakuan } & \multirow{3}{*}{ Pengulangan } & \multicolumn{7}{|c|}{$\%$ Parasetemia \pm SD } \\
\hline & & Hari & Hari & Hari & Hari & Hari & Hari & Hari \\
\hline & & 1 & 2 & 3 & 4 & 5 & 6 & 7 \\
\hline \multirow{2}{*}{$\mathrm{K}-$} & \multirow{2}{*}{5} & 51.43 & 59.96 & 63.03 & 62.51 & 74.56 & 69.52 & 82.39 \\
\hline & & \pm 7.50 & \pm 9.81 & \pm 10.4 & \pm 9.35 & \pm 10.63 & \pm 8.78 & \pm 4.44 \\
\hline \multirow{2}{*}{$\mathrm{K}+$} & \multirow{2}{*}{5} & 32.48 & 23.95 & 46.19 & 38.64 & 37.51 & 77.16 & 61.97 \\
\hline & & \pm 7.33 & \pm 3.9 & \pm 8.5 & \pm 6.73 & \pm 9.91 & \pm 5.84 & \pm 3.83 \\
\hline \multirow{2}{*}{$\mathrm{P} 1$} & \multirow{2}{*}{5} & 35.55 & 40.45 & 40.72 & 48.6 & 44.78 & 60.16 & 37.97 \\
\hline & & \pm 5.23 & \pm 6.15 & \pm 7.72 & \pm 10.79 & \pm 8.91 & \pm 7.51 & \pm 9.08 \\
\hline \multirow{2}{*}{$\mathrm{P} 2$} & \multirow{2}{*}{5} & 27.6 & 25.71 & 25.52 & 22.05 & 32.67 & 31.79 & 29.70 \\
\hline & & \pm 5.47 & \pm 1.02 & \pm 5.92 & \pm 4.60 & \pm 7.04 & \pm 4.49 & \pm 5.37 \\
\hline \multirow{2}{*}{ P3 } & \multirow{2}{*}{5} & 23.84 & 29.19 & 23.91 & 26.06 & 24.93 & 26.11 & 23.49 \\
\hline & & \pm 7.10 & \pm 6.87 & \pm 2.06 & \pm 1.11 & \pm 3.24 & \pm 3.31 & \pm 3.13 \\
\hline
\end{tabular}

Keterangan : K- : ( M. musculus terinfeksi

P.berghei + aquades); K+ : (M.musculus terinfeksi

P.berghei + klorokuin); P1:(M. musculus terinfeksi

P.berghei + fraksi n-heksana dosis efektif $0,028 \mathrm{~g}$

/kgbb); P2: ( M.musculus terinfeksi P.berghei + fraksi n-heksana dosis efektif 0,056 $\mathrm{g} / \mathrm{kgbb}) ; \quad$ P3 : (M.musculus terinfeksi P.berghei + fraksi n-heksana dosis efektif $0,084 \mathrm{~g} / \mathrm{kgbb}$ )
Dari Tabel 2, terlihat bahwa adanya perbedaan persen parasetemia setiap kelompok uji yang disebabkan oleh beberapa faktor yaitu faktor sampel, parasit dan $M$. musculus. Untuk faktor sampel, fraksi n-heksana daun $P$. canescens yang digunakan sebagai obat masih dalam dosis yang rendah sehingga masih banyak parasit yang mampu bertahan dan berkem- 
bang. Faktor parasit dikarenakan kemungkinan adanya mutasi gen. [10] akibat adanya gen yang resistensi dan sensitif terhadap obat tertentu. Faktor M.musculus dikarenakan adanya perbedaan sistem imun antar M.musculus yang dapat mem-pengaruhi kemampuan M.musculus pada saat mengeliminasi parasit.

Dilihat dari segi fisik M.musculus yang terinfeksi P.berghei, pada hari pertama hingga hari ke-7, terjadi beberapa perubahan seperti pada Gambar 2. Awalnya M.musculus tersebut masih sehat dan segar dan semakin hari semakin lemas, pucat, menggigil, bulu tubuhnya menipis dan ekornya pucat.
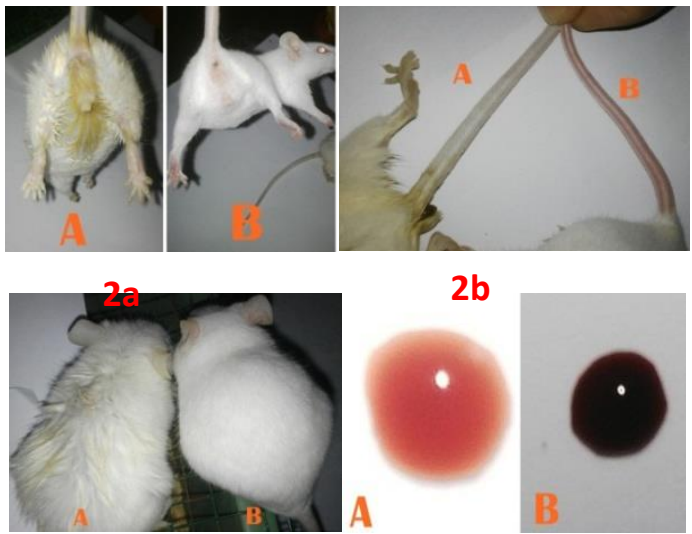

$2 c$

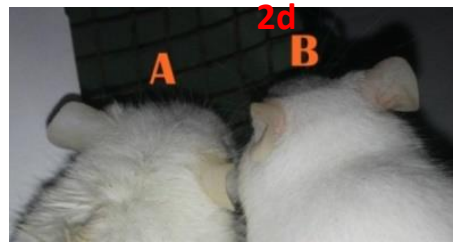

Keterangan :

$\mathrm{A}=$ M.musculus terinfeksi P.berghe

$\mathrm{B}=$ M. musculus Sehat

Gambar 2. Perbedaan M. musculus Sakit dan Sehat Ditinjau Dari Segi Fisik: (2a) Keadaan Perut (2b) Ekor (2c) Bulu (2d) Darah (2e) Telinga

Berdasarkan penelitian, fraksi n-heksana daun P.canescens memperlihatkan adanya perbedaan dan pengaruh terhadap penurunan $\%$ parasetemia pada $M$. musculus jantan pada setiap perlakuan yang disajikan pada Gambar 3.

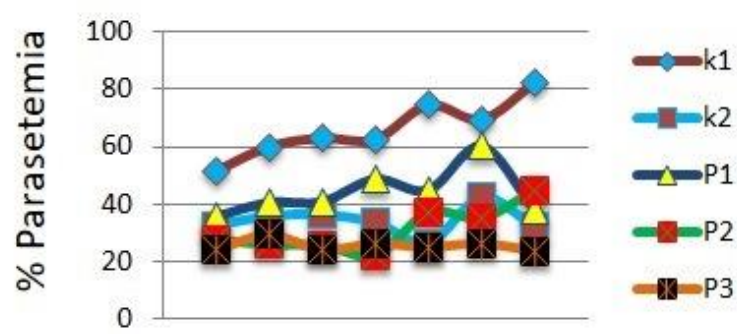

Gambar 3. Rata-rata \%Parasetemia Pada

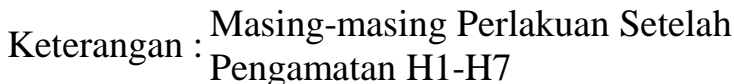

\begin{abstract}
K- $\quad$ :(M. musculus terinfeksi P.berghei + aquades)
$\mathrm{K}+\quad$ :(M. musculus terinfeksi P.berghei + klorokuin)

P1 :(Mus musculus terinfeksi P.berghei + fraksi nheksana dosis efektif $0,028 \mathrm{~g} / \mathrm{kgbb})$

P2 :(M. musculus terinfeksi P.berghei + fraksi nheksana dosis efektif $0,056 \mathrm{~g} / \mathrm{kgbb})$

P3 :(M. musculus terinfeksi P.berghei + fraksi nheksana dosis efektif $0,084 \mathrm{~g} / \mathrm{kgbb}$ )
\end{abstract}

Kelompok perlakuan tiga adalah kelom-pok perlakuan yang paling bagus karena pada kelompok perlakuan ini kenaikan \% parasetemia sangat kecil dibandingkan dengan kelompok perlakuan yang lain (Gambar 3). Kenaikan \% parasetemia kecil berarti \% hambatan partumbuhan parasit yang besar. Pada kontrol negatif, terlihat adanya kenaikan \% parasetemia, yang berlaku juga pada kontrol positif, perlakuan 1, dan perlakuan 2 yang mengalami kenaikan dan penurunan yang tidak signifikan. Semakin besar dosis fraksi n-heksana daun P.canescens yang diberikan maka akan semakin besar \% hambatannya. Hal ini dikarenakan adanya kandungan zat aktif dalam dosis tersebut yang mampu menghambat pertumbuhan parasit. Data persentase pertumbuhan dan penghambatan setiap perlakuan disajikan pada Tabel 4 .

Berdasarkan Tabel 4 terlihat bahwa \% penghambatan pada kontrol (-) sebesar 0\%, kontrol (+) sebesar $31.40 \%$, P1 sebesar 33,49\%, P2 sebesar $57.91 \%$ dan P3 sebesar 61.69\%. Kelompok P3 memiliki $\%$ penghambatan yang lebih besar dibandingkan dengan kelompok perlakuan yang lain.

Berdasarkan Tabel 5, data perhitungan \% parasetemia yang dianalisis menggunakan anova single faktor, memperlihatkan adanya pengaruh dosis yang diberikan terhadap Mus musculus jantan.

Tabel 4. Persentase Pertumbuhan dan Penghambatan Parasit Setiap Perlakuan

\begin{tabular}{ccc}
\hline Perlakuan & $\begin{array}{c}\% \\
\text { Pertumbuhan }\end{array}$ & $\begin{array}{c}\% \\
\text { Penghambatan }\end{array}$ \\
\hline K (-) & 5.16 & 0 \\
K (+) & 4.92 & 31.40 \\
P1 & 0.40 & 33.49 \\
P2 & 0.35 & 57.91 \\
P3 & -0.06 & 61.69 \\
\hline
\end{tabular}

Keterangan :

K- $\quad$ :(M.musculus terinfeksi P.berghei + aquades)

$\mathrm{K}+\quad$ :(M.musculus terinfeksi P.berghei + klorokuin) 
P1 :(M.musculus terinfeksi P.berghei + fraksi nheksana dosis efektif $0,028 \mathrm{~g} / \mathrm{kgbb}$ )

P2 :(M.musculus terinfeksi P.berghei + fraksi nheksana dosis efektif $0,056 \mathrm{~g} / \mathrm{kgbb}$ )

P3 :(M.musculus terinfeksi P.berghei + fraksi nheksana dosis efektif $0,084 \mathrm{~g} / \mathrm{kgbb}$ )

Dari hasil analisis, diketahui bahwa hari pertama (H1), kedua, ketiga, keempat, kelima, keenam dan hari ketujuh nilai F Hitung > F tabel sehingga H1 diterima. Hal ini menunjukkan bahwa adanya perbedaan rata-rata persen parasetemia yang nyata antar kelompok perlakuan.

Tabel 5. Hasil analisa anova single faktor

\begin{tabular}{llll}
\hline \multirow{2}{*}{ No } & \multirow{2}{*}{ F hitung } & \multicolumn{2}{c}{ F tabel } \\
\cline { 3 - 4 } & & $5 \%$ & $1 \%$ \\
\hline 1 & 6.04 & & \\
2 & 17.50 & & \\
3 & 23.16 & & \\
4 & 8.63 & 2.86 & 4.43 \\
5 & 26.04 & & \\
6 & 15.61 & & \\
7 & 7.72 & & \\
\hline
\end{tabular}

\section{KESIMPULAN}

Berdasarkan penelitian yang telah dilakukan maka dapat disimpulan bahwa Pengaruh pemberian fraksi n-heksana daun $P$. canescens terhadap jumlah parasetemia $M$. musculus jantan yang diinfeksi $P$. berghei menunjukkan adanya penurunan jumlah parasetemia pada $M$. musculus jantan. Pada dosis $0,084 \mathrm{~g} / \mathrm{kgbb}$ memiliki nilai rata-rata penurunan yang lebih signifikan dibandingkan dengan dosis 0,028 dan $0,056 \mathrm{~g} / \mathrm{kgbb}$. Hal tersebut menunjukkan adanya hubungan peningkatan dosis fraksi n-heksana daun $P$. canescens terhadap penurunan $\%$ parasetemia $M$. musculus jantan berbanding lurus dengan peningkatan dosis sampel.

Dilihat dari segi fisik, terdapat perbedaan antara M.musculus yang sehat dan M.musculus yang terinfeksi P.berghei yang dapat diamati dari segi ekor, bulu, daun telinga, darah dan bagian perut.

\section{SARAN}

Perlu penelitian berupa pengujian lanjut dengan dosis yang lebih besar dan mengisolasi senyawa aktif berdasarkan bioaktivitasnya secara in vivo dan in vitro.

\section{DAFTAR PUSTAKA}

[1] Mohamad H , Andriani Y , Bakar K, Siang CC, Syamsumir, DF Alias A and Radzi SAM, S, 2015, Effect of drying method on antimicro-bial, anti-oxidant activities and isolation of bio-active compounds from Peperomia pellucida (L) Hbk, Journal of Chemical and Pharma-ceutical Research, 7(8). http:// www.jocpr.com.

[2] Andriani Y, 2014, The Miracolous Mahkota Dewa, Article in Voyages of Discovery UMT 2: 9, Publisher : University Malaysia Terengganu, Kuala Terengganu

[3] Andriani. Y, Mohamad, H., 2013, Potential Therapeutic Lead Coumpouds From Our Local Coastal Forest, , The 26th Symposium of Malaysia Analytical Sciences (SKAM 26), Khuching Serawak Malaysia, 4-5 December.

[4] Andriani. Y, 2010, Study Correlation between antioxidant activity and total phenolics content of Phaleria macrocarpa leaves extract, UMTAS International conference, University Malaysia Terengganu (UMT) Kuala Terengganu Malaysia 6-8 Mei

[5] Yani, A.P. 2013. Kearifan Lokal Penggunaan Tumbuhan Obat Oleh Suku Lembak Delapan di Kabupaten Bengkulu Tengah, Bengkulu http://jurnal.fmipa.unila.ac.id/index.php/ semirata/article/viewFile/575/395.(diakses tanggal 17 November 2016).

[6] Ningsih, A. 2013. Potensi Antimikroba dan Analisis Spektroskopi Isolat Aktif Ekstrak NHeksan Daun Sungkai (Peronema canescens. Jack) Terhadap Beberapa Mikroba Uji. Molekul11(1):101-111, http://pasca.unhas.ac.id/jurnal/files/pdf (diakses tanggal 23 November 2016)

[7] Ibrahim, A., dan Hadi Kuncoro. 2012. Identifikasi Metabolit Sekunder dan Aktivitas Antibakteri Ekstrak Daun Sungkai (Peronema canescens Jack) Terhadap Beberapa Bakteri Patogen. Journal Of Tropycal Pharmacy and Chemistry. 2(1).

[8] Depkes RI. 2008. Pedoman Penatalaksaan Kasus Malaria Di Indonesia. D.J. Pengendalian. Jakarta. http://www.depkes.go.id/ download.php?file=download/pusdatin/ buletin/buletin-dbd.pdf

[9] Darmawan, R. 2014. Uji Aktivitas Antiplasmodium (Peronema canescens) terhadap Mus musculus Jantan Serta Implementasinya sebagai LKS Pada materi Protista. http://repository.unib.ac.id. 
[10] Badiaraja, P.H.2014. Uji Potensi Antipiretik Daun Muda Sungkai (Peronema canescens) Pada Mus musculus serta Implementasinya dalam pembelajaran sistem Imun di SMA. Skripsi: FKIP UNIB. http://repository.unib. ac.id.
Penulisan Sitasi Artikel ini ialah :

Andriani. F, Sundaryono, A. Nurhamidah, 2017, Uji Aktivitas Antiplasmodium Fraksi n-Heksana Daun Peronema canescens Terhadap Mus musculus. Alotrop, 1(1):33-38. 